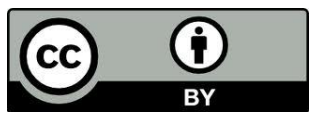

\title{
EDUCAÇÃO TEOLÓGICA PROTESTANTE E SEUS DILEMAS ATUAIS
}

\author{
Protestant theological educatrion and its current dilemmas
}

\begin{abstract}
Edson Martins
Mestre em Educação pela UFPR e Doutor em Ciências da Religião pela Universidade Metodista de São Paulo. Coordena o curso de Teologia da Faculdade Cristã de Curitiba e é professor nas
\end{abstract}

Faculdades OPET.

RESUMO: O presente artigo procura traçar um panorama da educação teológica protestante e seus dilemas atuais. Objetiva mostrar que a oficialização dos cursos de teologia por parte do Ministério da Educação - MEC - trouxe uma nova realidade para a educação teológica protestante, gerando dilemas difíceis de serem equacionados. Um deles é a dificuldade em abrir mão do modelo de educação teológica adotado até aqui pelas instituições protestantes. Outro dilema é quanto ao tipo de formação que os futuros obreiros do grupo religioso a que a instituição teológica pertence, visto que para muitas delas é importante manter a tradição e o modelo reprodutivista. O terceiro grande dilema é o do sustento, pois cada vez mais a manutenção das instituições fica mais pesada e a cargo dos brasileiros, cujos recursos para este fim são limitados. Por fim, há o dilema da formação do corpo docente das instituições teológicas protestantes, que necessita de professores com titulação reconhecida pelo MEC, mas teme as más influências que um professor formado em instituições seculares pode trazer para seus alunos.

Palavras-chave: Educação teológica. Protestantismo. Seminários.

\begin{abstract}
This article tries to give an overview of Protestant theological education and their current dilemmas. Aims to show that the formalization of courses in theology from the Ministry of Education - MEC - brought a new reality to the Protestant theological education, creating difficult dilemmas to be solved. One is the difficulty in giving up the theological education model adopted so far by Protestant institutions. Another dilemma is the type of training that future workers of the religious group to which the theological institution belongs, since for many of them it is important to keep the tradition and reproduction style. The third great dilemma is support because even more the maintenance of institutions is getting hard and in charge of the Brazilians, whose resources are limited for this purpose. Finally, there is the dilemma of the training of the teaching staff of Protestant theological institutions, which requires teachers with recognized titles by MEC, but fears the bad influences that a teacher trained in secular institutions can bring to their students.
\end{abstract}

Keywords: Theological Education. Protestantism. Seminary. 


\section{Intordução}

A educação teológica protestante no Brasil já possui uma longa história e está intimamente ligada à instalação das primeiras igrejas em solo brasileiro. Durante muito tempo poucas mudanças foram efetuadas. Porém, a partir do Parecer 241/99, do Conselho Nacional de Educação as coisas começaram a mudar. A análise de algumas destas mudanças é um dos objetivos deste artigo.

Neste artigo, por uma questão metodológica e de espaço mesmo, ao falar de protestantismo estaremos nos referindo às quatro principais denominações que no Brasil se instalaram a partir de 1850: os presbiterianos, os batistas, os metodistas e os luteranos, embora entenda que todos os evangélicos, de modo geral são oriundos da herança protestante.

Com a instalação destas referidas igrejas, os missionários viram a necessidade de preparar obreiros nativos para a evangelização do Brasil, surgindo assim os primeiros seminários protestantes, quase todos copiados em seus inúmeros detalhes do país de origem dos missionários.

Os primeiros diretores e professores destas instituições foram os missionários, que procuravam despertar vocações e investiam de forma mais incisiva nos jovens mais promissores.

O ensino ministrado nestas instituições, que receberam o nome de "seminários" era, com raras exceções reprodutivista, visto que a totalidade do material didático era importado do país de origem da denominação e aqui traduzido para o português. Com este material centenas de obreiros foram preparados nas instituições teológicas protestantes.

Porém, muitos bacharéis em teologia não sabiam o que fazer com seus diplomas fora dos limites eclesiásticos e começaram a clamar por um aproveitamento dos estudos feitos. Isto só vem a acontecer com a aprovação Decreto-Lei $n^{\circ} 1.051 / 69$, que permitia o aproveitamento de parte do curso de bacharelado em Teologia em Faculdades de Filosofia, Ciências e Letras. Com a abertura permitida por este decreto, muitos pastores aproveitaram para cursarem a licenciatura em Filosofia, permitindo-lhes lecionar, aumentando sua renda.

Mas é com o Parecer 241/99, do Conselho Nacional de Educação que a Teologia ganha oficialmente o status de curso universitário. Aí é que começam os problemas para 
as denominações e suas instituições. Estas, diante da abertura que o Parecer trouxe, se viram obrigadas a responder a algumas questões, que para algumas se transformaram em verdadeiros dilemas, que são:

a) O seminário, ao se transformar em faculdade teológica credenciada pelo MEC não perderá a sua essência?

b) Haverá interferência dos poderes públicos no ensino ministrado nestas instituições autorizadas?

c) Os formados não perderão de vista o caráter ministerial, assumindo uma postura profissional?

d) Onde conseguir professores preparados para atender as exigências legais para o reconhecimento do curso?

Estas e outras questões não menos importantes constituem-se no dilema da educação protestante no Brasil. Falemos um pouco de algumas delas.

\section{!. Dilema Novo}

Ensina-nos a Psicologia e a sociologia também, que tudo o que é novo provoca temor, principalmente nos mais velhos, pelas razões óbvias de que estes, na maioria das vezes, já estão acomodados com o estilo de vida que desenvolveram (KOENIG, 1982, p. 346). A reação ante as novidades introduzidas no mundo teológico brasileiro comprova isto.

Há muitos líderes que são contra a transformação de suas instituições de ensino em faculdades teológicas sem mesmo explicitar as razões. São contra porque isto representa algo novo, que certamente vai exigir mudanças e eles não estão dispostos a adaptar-se a uma nova realidade que não dominam.

Um dos fatores importantes na leitura da situação é a constatação de que em muitas instituições, a sua implementação foi inteiramente copiada de uma matriz estrangeira, geralmente dos Estados Unidos da América e continuam a reproduzir o modelo matricial. Mudar esta mentalidade de formação é sempre um grande problema, principalmente se a matriz estrangeira ainda mantém influência sobre a instituição no presente.

Para a instituição entrar no sistema federal de educação será necessário adaptarse às normas e regras da educação superior brasileira, e é aqui que começam as 
dificuldades para os administradores.

Eles têm de trabalhar com projeções pessimistas, de secularização da teologia, da profissionalização do ministério, da interferência estatal nos currículos dos cursos, da obrigatoriedade da aceitação de qualquer um na instituição, e por aí vai.

Um dos grandes pensadores protestantes alerta para o perigo da secularização da teologia, ao escrever que:

\begin{abstract}
A sociedade está mudando. As igrejas também estão mudando, porém, as instituições teológicas têm de satisfazer as exigências das autoridades universitárias ou das agências de credenciamento, cuja preocupação é fundamentalmente acadêmica, não missionária. Assim pois, as instituições teológicas não podem ir adequando seus programas e métodos às novas situações de missão em que vivem as igrejas. O reconhecimento lhes dá prestígio e um certo grau de profissionalismo, mas acaba impossibilitando a importante tarefa de preparar seus estudantes para os novos tempos (ESCOBAR, 1996, p. $73)$.
\end{abstract}

Escobar não está sozinho em suas preocupações. Outros líderes também estão.

Eles vislumbram as perdas, que certamente virão com a nova realidade. Mas não vislumbram as vantagens que certamente virão. É o que acontece quando mudanças aparecem.

\title{
2. O dilema do objetivo da formação teológica
}

Diante da pergunta: Para que serve a teologia? Muitas respostas podem ser dadas. Mas para as confissões religiosas mais tradicionais o objetivo ou a "serventia" da teologia é um só: preparar obreiros para as igrejas do grupo. Mão-de-obra que garanta a reposição de líderes e a demanda oriunda da expansão do grupo.

É visível a pressão exercida pela liderança dos grupos religiosos para que a educação teológica ministrada em suas instituições seja o mais reprodutivista possível. Assim, para esta liderança, aluno bom é aluno é aluno obediente, piedoso, que aceite ser "formado" de acordo com as necessidades da instituição. Aluno questionador é um perigo.

A maioria dos líderes das confissões protestantes conservadoras, ainda que tenham passado por um seminário, acabam valorizando mais a espiritualidade que o saber acadêmico. Pior: além de valorizar, acabam querendo impor às instituições esta visão de formação teológica, calcada mais na piedade que no conhecimento 
(MENDONÇA, 1984, p. 215).

Embora seja um texto do século XVII, as palavras de Philipp Jacob Spener, guardadas as devidas proporções, encontram concordância entre muitos líderes protestantes conservadores quando diz que "os professores devem demonstrar que os alunos preferidos são aqueles que, embora não tirando boas notas, levam vida de piedade. Os alunos piedosos deverão ser classificados como os primeiros e os únicos a serem aprovados" (1985, p. 70-71).

Rubem Alves (1982, p. 162) escreveu que pelo fato de que somente na igreja é que o diploma de bacharel em teologia pode ser transformado em salário, o obreiro fica refém da instituição, sem muita opção de trabalho, sujeitando-se muitas vezes a imposição e humilhações. Não é à toa que na maioria das denominações protestantes é supervalorizado o pastor de tempo integral (mesmo que mal sustente a família). Este profissional que se dedica inteiramente à sua igreja é tido como mais espiritual, mais dependente de Deus. Já quem exerce outra profissão é visto como quem não confia inteiramente em Deus por não pedir demissão do trabalho secular.

A novidade hoje é que com o diploma de bacharel em teologia reconhecido pelo MEC, além de trabalhar na igreja, o indivíduo pode prestar concurso público, fazer uma pós-graduação reconhecida e abrir novas possibilidades de trabalho. Logo, este ser religioso não é mais tão refém da instituição religiosa a que pertence.

Por isto é que está crescendo nas instituições teológicas o número de alunos que procuram o curso de teologia com o objetivo de ascensão funcional (principalmente no serviço público). E temos o caso dos já formados em outras áreas e que querem estudar teologia apenas para o aumento dos seus conhecimentos. Tudo isto incomoda a alguns membros da liderança, que são contra o reconhecimento dos cursos, que na visão deles teriam se desvirtuado dos objetivos primários.

\section{O dilema do sustento}

Este dilema acaba envolvendo os demais. Inicialmente, as instituições teológicas tradicionais, em sua maioria, começaram por iniciativa dos missionários e os recursos para a construção dos prédios e para a manutenção da instituição vinham de fora, do exterior. Os alunos pagavam mensalidades subsidiadas.

Por causa disto, as instituições eram muito criteriosas na captação de alunos, só 
aceitando aqueles que as convencessem de que eram realmente vocacionados, dando preferência aos que fossem da mesma confissão. Faziam isto porque não dependiam dos alunos para pagar as contas.

Com a saída dos missionários e a transferência da direção das instituições para os brasileiros, a situação ficou difícil para se administrar e foi agravada com o fato de que o processo de reconhecimento do curso faz com que as despesas das instituições subam consideravelmente.

Outro dado que precisa ser levado em conta é que como as mensalidades dos cursos livres eram baixas, muitas igrejas concediam bolsas integrais para os alunos e com isto mantinham-nos com as rédeas curtas, fazendo valer o antigo ditado: "quem paga, manda!"

Atualmente esta não é a realidade dominante. Com raríssimas exceções, o maior volume de recursos das instituições (salvo as exceções) é proveniente das mensalidades escolares. As instituições precisam desesperadamente aumentar o número de alunos. Para piorar, precisam disputá-los com as concorrentes. Consequentemente, as exigências na captação foram caindo dia após dia. Assim, a maioria dos alunos de teologia são trabalhadores, e estudantes do período noturno. Como são eles que pagam seus cursos, não ficam dependentes e nem tão obedientes aos seus pastores, o que lhes desagrada sobremaneira (MARTINS, 2004, p. 60).

O dilema se acentua ante a difícil escolha: Não procurar o reconhecimento do curso e manter a tradição e a pureza do ensino, mas correndo o risco de não ter alunos, que preferirão investir em um curso reconhecido que lhes dará novas oportunidades ou procurar o reconhecimento, correndo os riscos inerentes a essa escolha?

\section{4. $O$ dilema do corpo docente}

Este talvez seja o mais problemático de todos os dilemas. Acontece que quando uma instituição resolve reconhecer o seu curso junto ao MEC, precisa apresentar um corpo docente qualificado segundo os seus padrões, ou seja: que os cursos feitos pelos professores tenham validade oficial. O problema é que a maioria dos docentes em instituições teológicas possui o bacharelado em teologia na modalidade de curso livre. Só recentemente é que se regularizou o processo de validação destes cursos, chamado de convalidação. 
Mas o problema continua porque até recentemente (para não dizer até hoje) a maioria dos docentes eram pastores de igrejas locais, que faziam e fazem do magistério teológico apenas um bico, visto que, com raras exceções, não dá para viver apenas lecionando teologia. E como são mal remunerados, com um diploma sem validade oficial, poucos tem a oportunidade de se especializar, criando um corpo docente com bastante experiência prática, mas fraco nas pesquisas e nos questionamentos.

Mas há alguns que possuem diplomas de mestrado e doutorado feitos no exterior, principalmente nos Estados Unidos. Quando procuram as universidades para a convalidação, encontram muita resistência, seja porque o curso não atende os requisitos legais, seja por corporativismo dos departamentos das instituições.

Mas, com todas as dificuldades existentes, os professores estão procurando os poucos cursos de pós-graduação em teologia ou ciências da religião para se qualificarem. As instituições precisam deles para atender os requisitos legais.

Porém, frequentemente, estes cursos são oferecidos por instituições pertencentes a confissões diferentes da sua. Isto faz com que parte da liderança o veja com certa desconfiança, com medo de que vá desvirtuar os alunos sob a sua docência. É frequente a crítica de que estes professores qualificados são apenas teóricos, sem experiência prática e, portanto, sem autoridade para ensinar futuros pastores.

Estes, por sua vez, sabem que são necessários às instituições pela qualificação que possuem, mas sabem também que são vistos com desconfiança e até com certo desprezo por grande parte da liderança, que os considera um "mal necessário".

A realidade é que o cenário da educação teológica brasileira mudou com o Parecer 241/99. Não dá para ignorar isto. As instituições teológicas protestantes estão sendo instadas a uma tomada de posição e estão fazendo, de acordo com suas conveniências.

\section{Considerações finais}

A meu ver, é possível fazer uma teologia de qualidade em um curso reconhecido. Uma teologia que leve os alunos à reflexão e às mudanças necessárias. Mas defendo que a teologia confessional atenda pelo menos em parte aos anseios da mantenedora, mas não sendo apenas um ensino reprodutivista, ou no dizer de alguns, uma '"fábrica de pastores", mas um espaço onde as instituições possam buscar subsídios 
para enfrentar seus problemas cotidianos.

Creio que, além da apreensão, a nova realidade trouxe um grande desafio: fazer uma teologia que não seja subjetiva, sectária, hermética e estereotipada e nem puramente acadêmica, teórica, distanciada das igrejas e da realidade social onde o povo exercita a teologia e consequentemente, a fé.

Se isto é possível só o tempo poderá dizer. A educação teológica protestante ainda está no processo de mudanças. Levará tempo até que se cristalize uma realidade permanente, se é que isto vá acontecer um dia.

\section{Referenciais}

ALVES, Rubem Azevedo. Dogmatismo e tolerância. São Paulo: Edições Paulinas, 1982.

ESCOBAR, Samuel. Fundamento e finalidade da educação teológica na América Latina. In: Revista Voz Scripturae. São Paulo: Vida Nova, v. VI, nº 1, p. 49-78, mar. 1996.

KOENIG, Samuel. Elementos de Sociologia. Rio de Janeiro: Zahar, 1982.

MARTINS, Edson. Instituição teológica: uma visão de seus principais componentes.In: KOHL, Manfred Waldermar; BARRO, Antonio Carlos. Educação Teológica transformadora. Londrina: Editora Descoberta, 2004, p. 44-78.

MENDONÇA, Antonio Gouvêa. O celeste porvir - A inserção do protestantismo no Brasil. São Paulo: Paulinas, 1984.

SPENER, Philipp Jacob. Pia Desidéria. São Bernardo do Campo: Imprensa Metodista, 1985.

Recebido: 26/07/2012

Received: 07/26/2012

Aprovado: 28/11/2012

Approved: 11/28/2012 